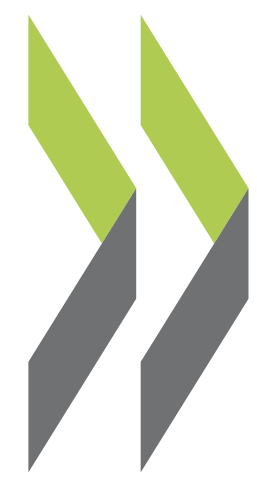

PEB Exchange, Programme on Educational Building 2003/14

\title{
Clicks, Bricks and Spondulicks
}

\section{Kenn Fisher}

https://dx.doi.org/10.1787/645201705763 


\section{CLICKS, BRICKS AND SPONDULICKS}

"Clicks, Bricks and Spondulicks" is the title of a seminar organised by PEB to examine the relationship between the built learning environment and information and communications technology (ICT), as well as cost implications. The meeting sought to determine whether educational buildings and ICT should continue to be seen as separate entities competing for the same funds, or whether they should be treated as one holistic component of educational infrastructure. The international seminar, held in Brisbane, Australia, in March 2003, concentrated primarily on vocational training and higher educational buildings. A full report with references will be available soon at www.oecd.org/edu/facilities

The seminar presented benefits of integrated capital planning strategies, taking into account life cycle expectancies and ICT advances such as online delivery; modes of knowledge production and flexible delivery; government policies and implications for planners; and implications for policy-makers.

\section{Integrating ICT with building planning}

Possibly one of the most critical issues faced in integrating ICT planning with building planning is the difference in their life cycle expectancies: for educational buildings it is ten to 15 years for their interiors (in the commercial sector more like seven to ten years) whereas in ICT it is closer to three to four years. The balance between the two is not only played out in funding strategies but also in social contexts. How to sustain communities of learners in both face-to-face contexts and virtual contexts is a key factor.

A seminar presentation which focused on the Australian Science and Mathematics School, sited on the campus of Flinders University in South Australia, outlined the ways in which many issues are tackled in an integrated way. The school facilitates the teaching and learning of mathematics and science in a research environment where teachers engage in staff development, where research is carried out into new technology-enhanced pedagogies and where Flinders University science faculty staff foster in students a willingness to pursue learning and careers in science and mathematics. Students spend time equally in the school, the university facilities including laborato- ries and cafeterias and in the community studying action research projects. Staff in the school are challenged to teach in an innovative student-centred environment in a building with no traditional classrooms or laboratories. Staff development is seen as a critical part of the success of the school, and the staff are trained in how to use the building itself as a "learning tool", in much the same way as they are already trained in the use of information and communications technology.

Other seminar examples presented include the Singapore Republic Polytechnic, which is to be a completely wireless campus based on the principle of problem-based learning, and the RMIT University Mode 2 knowledge study. These illustrated how pedagogy, ICT, the educational building and partnerships with the community are part of a seamless whole.

Online delivery has seen significant investment the world over and the likely impact of e-learning on the built learning environment is yet to be fully understood. Key elements of an extensive online delivery programme in New South Wales presented at the seminar included cross-organisational collaboration in the development of learningware, with all materials shared across systems, accessing courses not otherwise available at the local campus, together with building Web design skills capacity for the long term across the organisation. The online "rollout" also improved flexibility and student access to vocational education study programmes and helped to create enhanced and enriched learning experiences using blended learning and all-online delivery formulas. The project objectives expected that a return on investment would be achieved from a reduction in capital infrastructure overheads and the incorporation of learningware in commercial, local and international training partnerships and licensing arrangements. Significant growth in interstate and international student programmes is expected, as "the Internet knows no boundaries".

\section{Modes of knowledge and flexible delivery}

Two different modes of knowledge defined in ongoing research of how new knowledge is produced are reflected in campus planning. Mode 1 knowledge is based on traditionally accepted notions of academia which are essentially discipline-based, whereas Mode 2 knowledge "operates within a context of application. Here problems are not confined within a disciplinary framework. Knowledge production is trans-disciplinary rather than mono/multi-disciplinary and is carried out in non-hierarchical, heterogeneously organised forms that are essentially transient. It involves the close interac- 
tion of many actors throughout the process of knowledge production and as a result becomes more socially accountable and thus becomes diffused throughout society." 1

Within traditional campuses, educational institutions are largely constituted in Mode 1 format, with classrooms, laboratories and seminar rooms predominantly related to faculty disciplines. Mode 2 facilities are more responsive to collaboration, transience and informal learning but they also make greater use of technology rich environments such as seen in the flexible learning centres emerging in Australian higher education campuses.

The Queensland University of Technology (QUT) is in the process of embracing such a Mode 2 approach with its Kelvin Grove Urban Village. This development will "create a community which links home, work and learning environments to foster a vibrant, diverse and sustainable way of life." Within that complex (currently

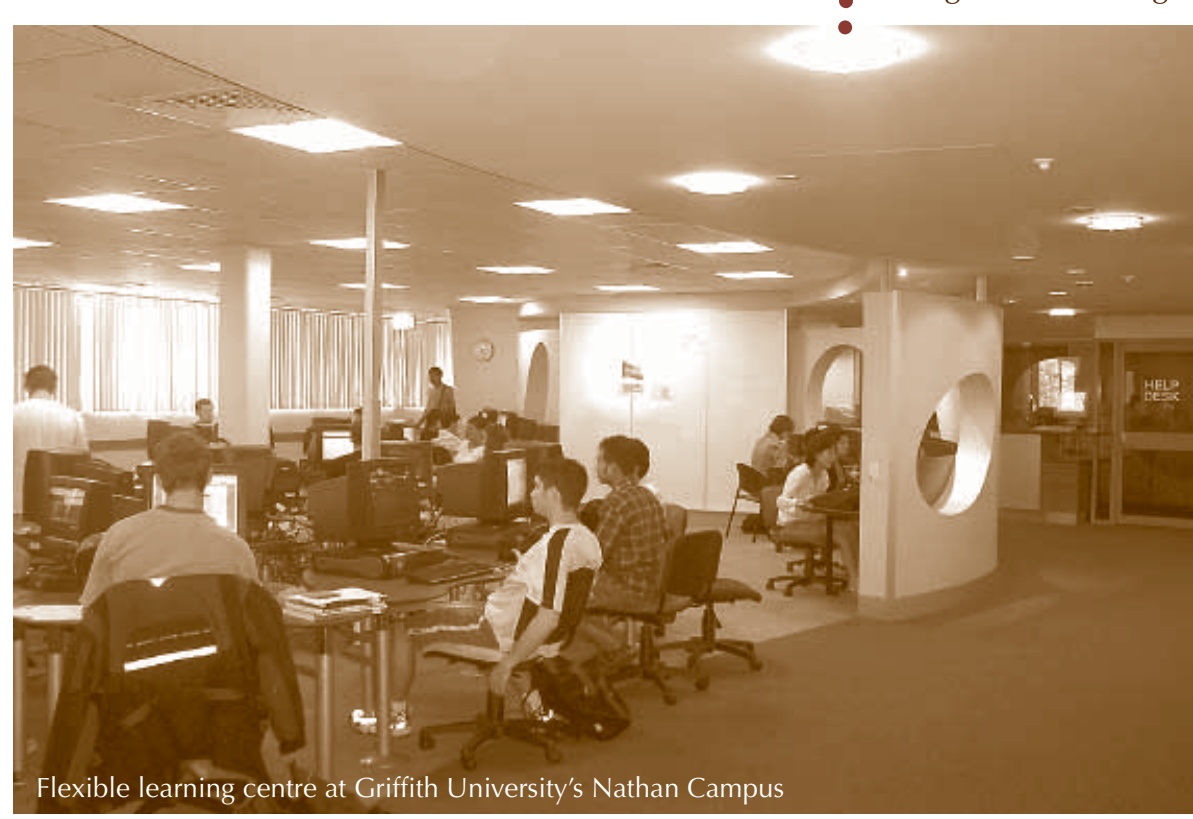

ces. $13 \%$ of students believe that they are no longer disadvantaged if they do not attend class and $7 \%$ of staff believe that they have a lighter workload. This commitment to flexible learning is evident in the significantly differing balance between ICT and buildings compared with the implied national average in Australia as demonstrated in funding applications specifically for innovative projects (note that university applications may have concentrated on built projects rather than software development projects which could skew the data). The percentages in the table below show the relative breakdown of funding for buildings, computing equipments and course development. under construction) sits the Creative Industries Precinct: "A purpose built, hi-tech site, the Precinct will be a centre of creative experimentation and commercial development, made possible by 24/7 all year around access, with wired and networked facilities, flexible working environments and exciting public spaces resulting in a vibrant community of like-minded individuals." ${ }^{2}$

Also at QUT, due to a need to increase floor space, it was decided to integrate both the building and ICT programmes in the capital planning process to achieve a coherent asset management planning strategy, to foster

\section{$\bullet$}

1. Gibbons, M., C. Limoges, H. Nowotny, S. Schwartzman, P. Scott and M. Trow (1994), The New Production of Knowledge - the Dynamics of Science and Research in Contemporary Societies, SAGE Publications Ltd, London.

2. Queensland University of Technology, Site Visit, Kelvin Grove Urban Village Overview, OECD/PEB "Clicks, Bricks and Spondulicks" seminar, Brisbane, March 2003, www.kgurbanvillage.com.au

3. Davis, G. (2003), "Bricks or Clicks, or Bricks and Clicks?: Debate on Progress in Two Australian Universities", Griffith University Case Study, Paper presented at OECD/PEB "Clicks, Bricks and Spondulicks" seminar, Brisbane, March. 


\begin{tabular}{lc|c} 
& $\begin{array}{c}\text { Australian Government } \\
\text { Special Capital } \\
\text { Development Pool }\end{array}$ & $\begin{array}{c}\text { Griffith } \\
\text { University }\end{array}$ \\
\hline Buildings & $64 \%$ & $10 \%$ \\
$\begin{array}{l}\text { Computing hardware } \\
\text { and networks }\end{array}$ & $25 \%$ \\
$\begin{array}{l}\text { Software and } \\
\text { content development }\end{array}$ & $11 \%$ & $65 \%$ \\
\hline
\end{tabular}

\section{Government policies and implications for planners}

There are emerging examples worldwide of PEB member countries focusing government policy more closely on ICT. In the Netherlands, for example, the Dutch education system launched a high speed electronic network system across the country between 1996 and 2002, where all educational institutions and student homes were linked by broadband networks. The project, called Kennisnet, attempted to tackle the issue of shared language across the system and provided funds for teacher development. It has not been without its problems however as, although "a success in terms of its business case, the opportunity to embrace teaching methods and to maximise the offerings of the network has yet to take place, as people didn't want to confront the education system." 4

In Japan this reluctance to change and capitalise on ICT has been managed through recent legislation. In 2000, the government introduced the Fundamental Law on the Formation of an Advanced Information Network Society (IT Fundamental Law). This was followed in 2003 by the establishment of the e-Japan Strategy, the e-Japan Priority Plan and the e-Japan 2002 Programme, all of which were designed to actively promote IT in the community. In the higher education sector the government has introduced increased numbers of IT courses for professionals, and the use of lectures over the Internet has been recognised as a legitimate form of lecture. Nevertheless, some problems are still recognised: "Some have pointed out (the increased potential for the) isolation of individuals, weakening of human relations, lack of natural and social experiences, the proliferation of harmful information and moral hazards and regulation problems on networks as negative effects of the IT revolution." It was suggested that one direct way out of this problem is greater interdisciplinary planning across government agencies and with industry. ${ }^{5}$
Planners also have to deal with the myriad realities of what forms of ICT should be adopted in the short and long terms, the cost benefits of which path is chosen and the whole of life costs of the options. At the University of Quebec in Montreal this issue was faced recently in the decision needed to upgrade telephony and computer data systems. The $100 \mathrm{~km}$ of fibre optic network needed upgrading to support teaching, research and administrative capabilities; concurrently the telephone system of 5000 lines was close to retirement and not able to be supported by manufacturers for much longer. One option for their replacement was VolP, or voice over Internet protocol. This seamless system provides flexibility for collaborative teaching and research through its integrated communications, with voice being given a priority over the system. Such an integrated system was considered by the university to offer greater productivity, to save money by purchasing the combined system rather than upgrading two separate systems, to improve reliability and to protect future network investments.

\section{Implications for policy-makers}

There is a range of issues that stand out for immediate consideration by policy-makers. The key ones would appear to be the following:

Integrating capital planning processes for both ICT and building infrastructure - Intelligent buildings, building management systems, passive and active environmentally sustainable systems and ICT are all merging within the building fabric as one technology. Building planning, design and management and ICT should be planned seamlessly. National funding authorities might consider extending the requirement for capital management plans for campus developments and maintenance to include ICT procurement and renewal.

Finding the correct balance in funding ratios between ICT and buildings - There appears to be little data or performance measures available comparing, contrasting and tracking the balance of investment between ICT and educational buildings. Real difficulties are faced in collating data for educational buildings that is reliable,

4. Stuebing, S. (2003), "Return on Learning: Managing the Symbiotic Relation between Space, Place and Access in Tertiary Education", Paper presented at OECD/PEB "Clicks, Bricks and Spondulicks" seminar, Brisbane, March.

5. Mori, M. and S. Seto (2003), "The National Programmes of Japan for the Promotion of IT at School", Paper presented at OECD/PEB "Clicks, Bricks and Spondulicks" seminar, Brisbane, March. 


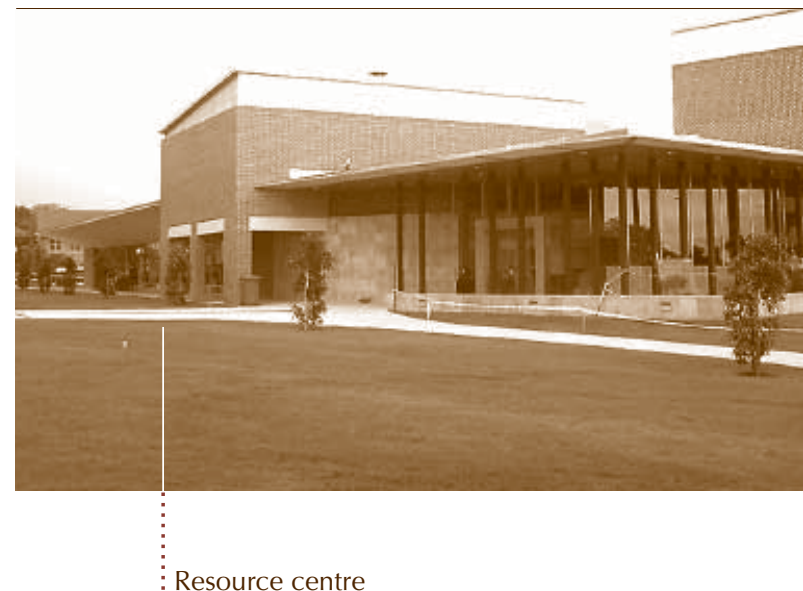

consistent and current across intra-national and international boundaries. Countries should consider the need for performance measures for educational buildings, particularly in light of accrual accounting and increasing maintenance liabilities. This data can be collated together with ICT investments with the integration of the two providing a much clearer and comprehensive picture of the investment in capital expenditure in post-secondary education.

Developing Mode 2 learning and research environments - Mode 2 learning environments are critical to maximising the extent of student-centred learning and lifelong learning through ICT as an enabler. Many existing campuses are approximately 90:10 in terms of Mode 1:Mode 2; whilst the correct balance is unknown it is likely that many programmes will always be taught in Mode 1 contexts. However, capital management plans should explore the balance between the two, and link this balance to the pedagogical practices especially related to flexible delivery, professional development programmes, academic business plans and infrastructure quality performance reviews of each institution.

Balancing distributed and central learning spaces Large numbers of new campuses are being opened, often accompanied by the closure of others, reflecting both demographic change and the cost of operating less than optimal sites. Learning centres or portals do not necessarily need to be associated with traditional core campuses. Indeed, to optimise the impact of lifelong learning and the re-entry of disaffected students, non-core campus learning centres might well become a norm. Distributed learning models supported by ICT and tutors should be considered as part of a capital management plan and as a valid means of serving dispersed and diverse community needs.

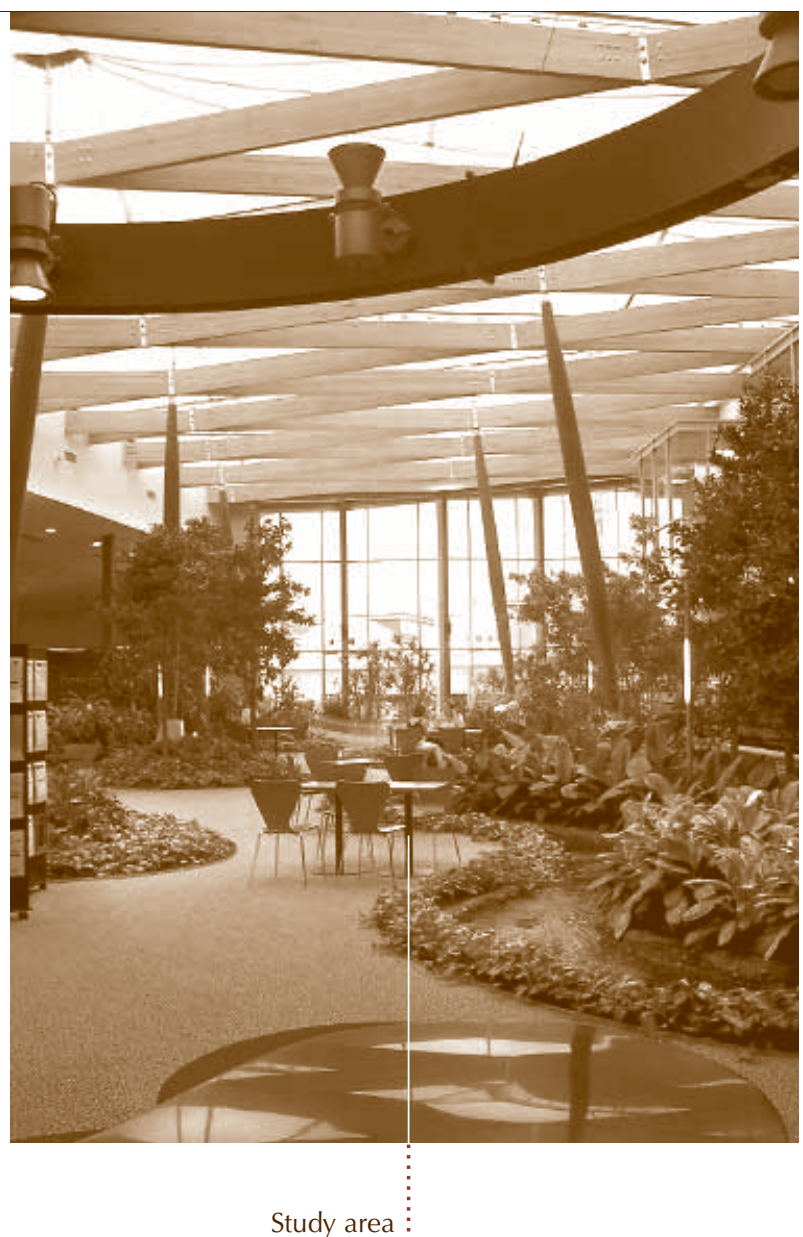

Implementing new performance measures for educational buildings - Managers of physical assets and planners at regional, national and global levels have continued to struggle with performance measures for educational buildings. Rather than pursue the continual challenge of trying to get countries to account for their building assets in a consistent and structured form, usually complicated by national accounting requirements, it might be time to explore other performance measures. The qualitative level of measuring learning outcomes per square metre, rather than simply the number of student hours per square metre, could become a new performance indicator of educational buildings and the associated ICT, as recommended by Susan Stuebing (2003).

Increasing professional development of staff - Professional development programmes have traditionally been associated with pedagogy, curriculum, finance, management and ICT training. It might well be time to examine the implication of space and place in teaching, learning and research, to provide a deeper understanding of how they interact. The classroom, seminar room and lecture theatre all continue to feature prominently in education 


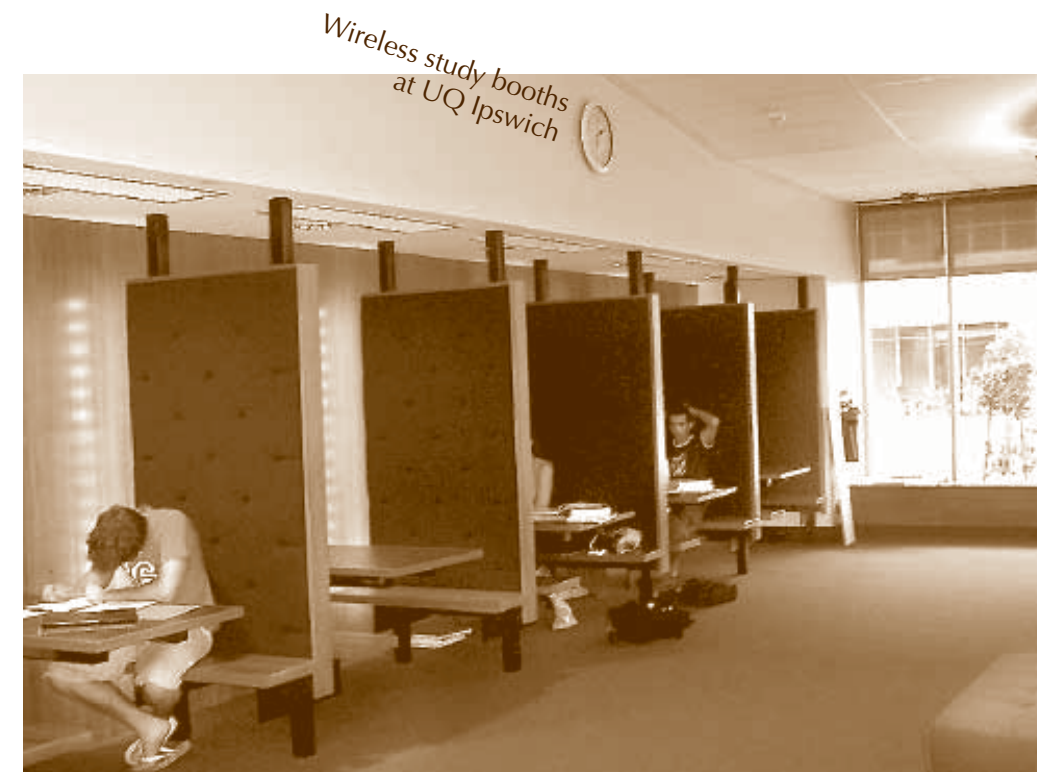

-

and training, despite the impressive impact of ICT on learning and teaching and the rather few examples of flexible learning illustrated at the seminar in Brisbane.

Extending government funding policies to foster innovation - Funding programmes need to be extended to restructuring existing buildings and campuses to include innovative teaching, learning and research methods. Innovative funding programmes normally favour new buildings; thus a refocus towards funding innovations within existing physical fabric and how it can be reconfigured to meet the challenges of new and emerging ICT would be timely.

Planning for future uncertainty - The methods adopted in traditional and rigorous strategic planning are being overtaken by rapid developments in ICT, emerging models of flexible learning, globalisation and the difference between the lead times and life cycles of both ICT and the built environment. What is now required is a more flexible approach to planning and budgeting. In this scenario much more collaboration is required, across disciplines, and in a continuing conversation which is reflexive. Further, planners in association with the operational staff must interact constantly during this process.

\section{Outcomes}

Current practise suggests that return on investment is a key assessment criteria based on the building life cycle and residual value. This philosophy is in contrast with the reinvention of education over the past decade which challenges us to be concerned with "return on learning" rather than "return on investment". Therefore, new assessment definitions and methods need to be developed to
-

- better recognise the educational "eco-system" in which our decision-making thrives. As Stuebing notes, an educational institution which is in tune with current market-based knowledge production articulates its operation in a business case, which optimises costs, as the mix of context (the combined digital and physical environment) and assistance, and value added (learning effect).

In the national arena, policy development might focus on funding strategies for innovative projects (particularly refurbishment) and could also support increased research studies such as Australia's Clicks on Bricks study. National ministries of education might also examine ways to develop new performance measures for both educational buildings and ICT infrastructure, particularly related to learning, teaching and research outcomes.

On the international stage there is clearly a need for more benchmark studies on educational buildings and ICT.

Perhaps the most powerful message coming from this seminar is that the two critical elements in learning infrastructure - educational buildings and ICT - should be seen as one entity, for they are both learning technologies albeit with differing life expectancies and life cycles. They should not be seen as competing for funds but as collaborating in ways which will see limited resources used in balance and to the best effect in terms of student learning outcomes.

Report by Kenn Fisher

E-mail: kenn_fisher@yahoo.co.uk 